\title{
Investigation of Near Flicker Source Impact on the Dynamic Performance of FCWECS
}

\author{
A. M. Shiddiq Yunus \\ Mechanical Eng. Department, \\ Energy Conv. Study Prog. \\ State Polytechnic of Ujung Pandang \\ South Sulawesi, Indonesia \\ shiddiq_96@yahoo.com.sg
}

\author{
Yasser M. Alharbi \\ Ministry of Higher Education, \\ Saudi Arabia \\ King Abdullah scholarship \\ Program \\ y.alharbi77@gmail.com
}

\author{
A. A. Siada, and M. A. S. Masoum \\ Electrical and Computer Eng. \\ Department \\ Curtin University \\ Perth, Western Australia \\ a.abusiada@curtin.edu.au, \\ m.masoum@curtin.edu.au
}

\begin{abstract}
The number of full converter wind energy conversion system (FCWECS) connected to existing electricity grids has significantly increased worldwide during the last two decades. One of the common power quality issues associated with wind turbine generator (WTG) is the voltage flicker which can be caused due to wind gust. It is pivotal for the existing or the new construction of the WTG to comply with the power quality standards. Although, with the advance in WTG technology and control systems, the flicker due to wind speed fluctuation can be mitigated, flicker can still be caused as a result of load pulsation such as arc furnaces, resistive welding machines and compressors. In this paper, the near flicker source impact on the connected WTG performance is investigated and the compliance of the WTG with the recent grid codes under such disturbance is highlighted.
\end{abstract}

Index Terms - FCWECS, Flicker, and Fault ride through

\section{INTRODUCTION}

Wind energy is one of the most promising renewable energy resources in the world. The global wind energy installed capacity has been increased from $2 \mathrm{GW}$ at the end of year 1990 to 94 GW by the end of year 2007. In 2008, electricity generation using wind power has reached $1 \%$ of the global electricity generation and by the year 2020 , it is expected that wind power will provide about $10 \%$ of the global electricity [1]. There are two main types of wind turbine generator; fixed-speed and variable speed wind turbines. Variable speed wind turbines are commonly used than fixed speed wind turbines due to many advantages that include the ability to track 5\% more power than fixed speed turbines and its capability to reduce the impact of transient wind gusts and subsequent fatigue which cannot be done by fixed speed turbines [2]-[3]. One type of the variable-speed wind turbines is the direct-drive variable speed wind turbine with multi-poles synchronous generator that is known as full converter wind energy conversion system (FCWECS). The wind energy market trend shows that FCWECS has been increased by about $20.3 \%$ in 2002 [4]. In this type, a

This work is supported by the Higher Education Ministry of Indonesia (DIKTI) in collaboration with the State Polytechnic of Ujung Pandang, Makassar, Indonesia, Ministry of Higher Education, Saudi Arabia and Curtin University, Perth, Australia. synchronous generator is connected to a three phase diode rectifier and a chopper as shown in Fig. 1. In case of rotor speed variation due to wind gust, the voltage level at the $\mathrm{dc}$ side of the diode rectifier will change. A step-up chopper is used to adapt the rectifier voltage to a pre-set dc-link voltage level to maintain the voltage at the point of common coupling (PCC) at constant level [2].

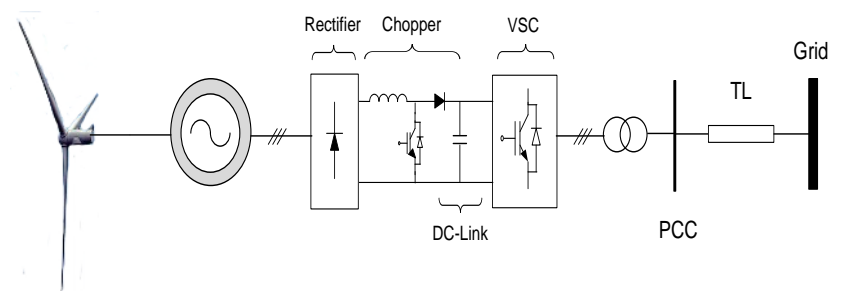

Fig. 1. Typical configuration of FCWECS

Reliability of power systems has become an important issue especially with the global trend to develop smart electricity grids and with the day-by-day increase in power demand with various types of non-linear loads and the penetration of distributed energy resources. It is estimated that the required amount of power generation in 2030 is about 28,930 TWh [5]. Power quality is one the most important issues that must be considered in the design of any future power systems. Considering its importance, number of key books that mainly concentrate on the power quality issues sources, impacts and various control techniques have been published in the literature [6]-[11]. Reference [11] defines power quality as the measure, analysis, and improvement of the bus voltage to maintain a sinusoidal waveform at rated voltage and frequency. One of the common power quality issues is the power line flicker which is caused due to continuous change in the magnitude of the load current that leads to voltage variation [11]-[12]. In [6] and [13], flicker is classified as a large and unpredictable event responsible for about $60 \%$ of the power quality problems affecting both the electric utilities and end users alike.

Commonly, flicker is caused by a load pulsation such as arc furnace, resistive welding machines, compressors, etc. [14]. If voltage fluctuation reaches lamp loads, the flicker can inconveniently cause epileptic attacks for photosensitive persons [15]. Moreover, this voltage fluctuation in power systems may cause disparaging effects with substantial costs such as disruption to industrial production processes. 
However, the physiological effect of flicker is the most important as it affects the ergonomics of the production environment, causing operator fatigue and reduced concentration levels [12].

Most of literatures studies about FCWECS considered its performance during various grid disturbances, converter internal faults and short circuit at the transmission line [16]-[21]. Although there are few studies in the literatures about the impact of flicker due to wind speed variation on WTG systems [22]-[25], no attention has been given to study the impact of flicker sources such as arc furnace connected close to the PCC of a FCWECS. In this context, five WTGs are simulated in this study and are connected to the grid through a $50 \mathrm{~km}$ transmission line as shown in Fig. 2. The grid is represented by an ideal sinusoidal voltage source of constant voltage and frequency. The flicker source is simulated as a variable load connected to the PCC through a step up transformer and a $2 \mathrm{~km}$ transmission line. Parameters of the system under study are provided in Appendix.

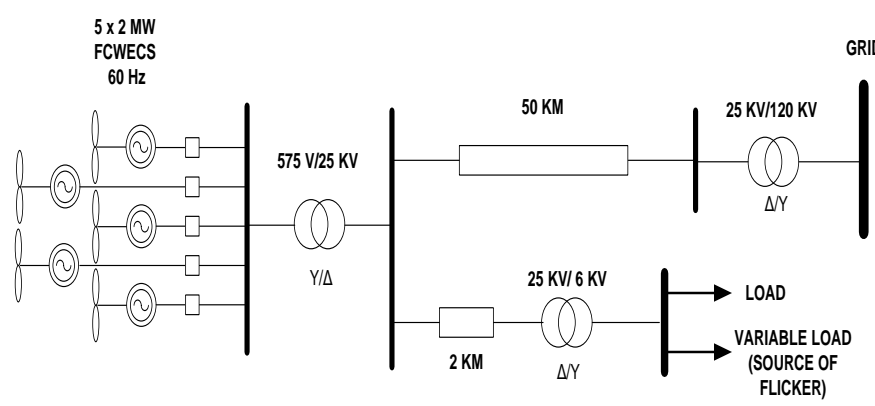

Fig. 2. System under study

\section{Voltage Ride Through}

One of the most important parameters of connected WTGs to the grid is the voltage profile at the PCC. Most of developed countries have designed their own grid codes that include regulation for low voltage ride through (LVRT) and high voltage ride through (HVRT) at the PCC. In this paper, The voltage ride through (VRT) of Spain and US grid codes shown in Fig. 3 and Fig. 4 respectively [26] are used to investigate the compliance of the FCWECS with both codes during voltage flicker at the PCC.

The VRT of Spain grid code at the PCC shows that the maximum permissible HVRT is $130 \%$ of the nominal voltage that lasts for a maximum of $0.5 \mathrm{~s}$ from the instant of fault application after which the maximum allowable voltage level is limited to $120 \%$ for the next $0.5 \mathrm{~s}$. $1.0 \mathrm{~s}$ after fault occurrence, voltage level must be limited within the range of $90 \%-110 \%$. The minimum voltage drop allowed in this grid code is $50 \%$ which lasts for $0.15 \mathrm{~s}$ from the instant of fault occurrence after which the permissible voltage level is increased to $60 \%$ for $0.1 \mathrm{~s}$. The low voltage restriction then ramps up to $80 \%$ after $1 \mathrm{~s}$ from fault application and reaches the normal condition in $15 \mathrm{~s}$ from the instant of fault occurrence. If the voltage profile does not comply with the VRT shown in Fig. 3, the wind turbines have to be disconnected from the grid to avoid any catastrophic failure to the wind turbine.

According to the US VRT grid code shown in Fig. 4, the maximum allowable voltage must be limited to $120 \%$ for a maximum duration of $1 \mathrm{~s}$ that drops by about $3.3 \%$ every $1.0 \mathrm{~s}$ until reaching 4.0s from fault occurrence. The LVRT of the US grid codes allows the voltage to be at zero level that could last for a maximum duration of $0.15 \mathrm{~s}$ after which the voltage must be gradually increased to $90 \%$ at around 1.75 s from the instant of fault application. The normal operation for US VRT grid code lies between $95 \%-105 \%$. If the voltage profile violates the constraints of both HVRT and LVRT, the WTGs must be disconnected from the grid.

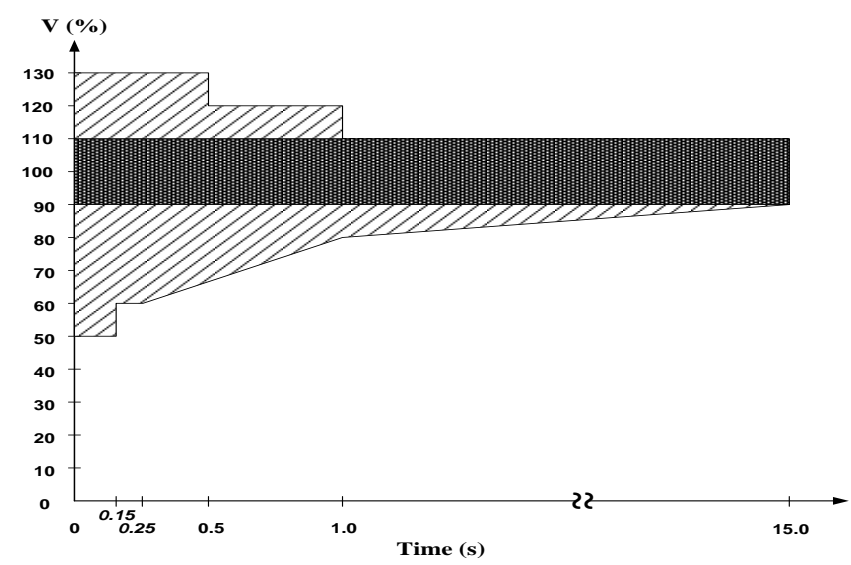

NORMAL OPERATION

SHOULD NOT DISCONNECT IN 1-, 2-, OR 3-PHASE FAULT

MAY DISCONNECT BY PROTECTION RELAYS

Fig. 3. VRT of Spain grid code
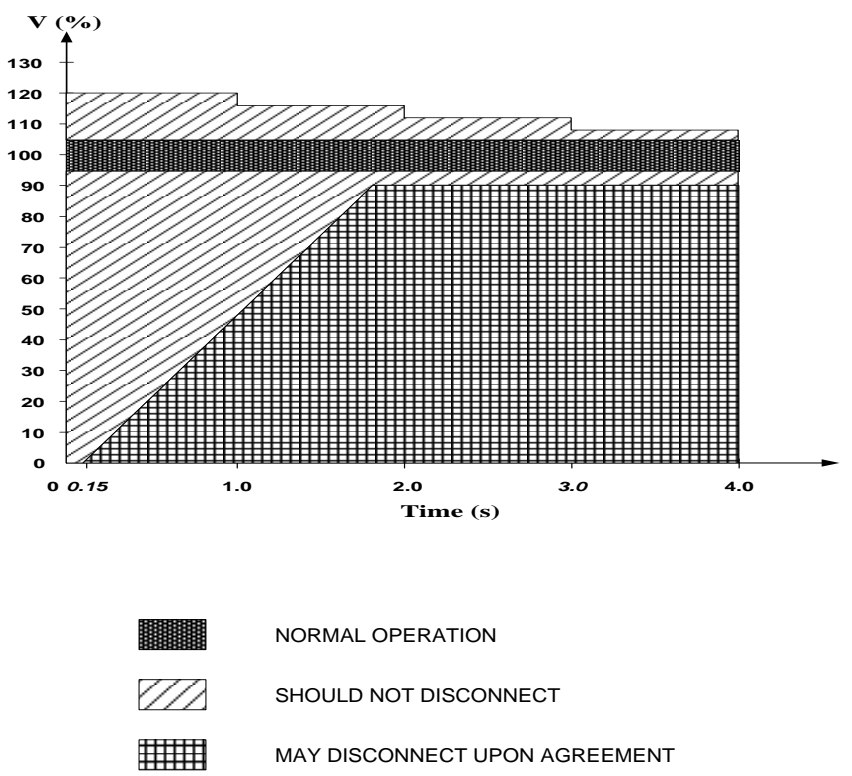

Fig. 4. VRT of US grid code 


\section{Simulation Results}

In this paper, a variable load is simulated as a flicker source and is adjusted to generate a fluctuating load at $\mathrm{t}=4 \mathrm{~s}$ and lasts for $3 \mathrm{~s}$.

Since the flicker source is located close to the WTG, the generator output power exhibits rapid oscillation with a frequency of $10 \mathrm{~Hz}$ during the flicker disturbance as shown in Fig. 5(a). The maximum overshooting of the generated power is almost reaching $120 \%$ that is may not be acceptable for many grid codes [4]. Although the overshooting of the instantaneous generated voltage shown in Fig. 5(b) is within permissible limits, the oscillation may lead to power quality issues. The DC link voltage shown in Fig. 5(c) also experiences a rapid oscillation with an overshooting level under commonly safety margin of $1.25 \mathrm{pu}$ of the nominal level however, the rapid oscillation could lead to the blocking of the converter to avoid possible damages to the capacitor [27].

As shown in Fig. 5(d), voltage profile at the PCC during flicker event is experiencing oscillation at a rate of $10 \mathrm{~Hz}$ and maximum overshooting that violate the maximum limit of Spain HVRT at around $\mathrm{t}=4.6 \mathrm{~s}$. Also, the $\mathrm{PCC}$ voltage profile violates the HVRT limit of the US VRT grid code as soon as the flicker disturbance starts. In this case, WTG must be disconnected from the grid to avoid any possible catastrophic damage to the WTG. Fig. 5(e) shows a zoomed area on the low voltage limit of the voltage at the PCC. The figure shows that, both LVRT of Spain and US are also violated during the flicker event. This will activate the protection systems to isolate the WTGs from the grid.

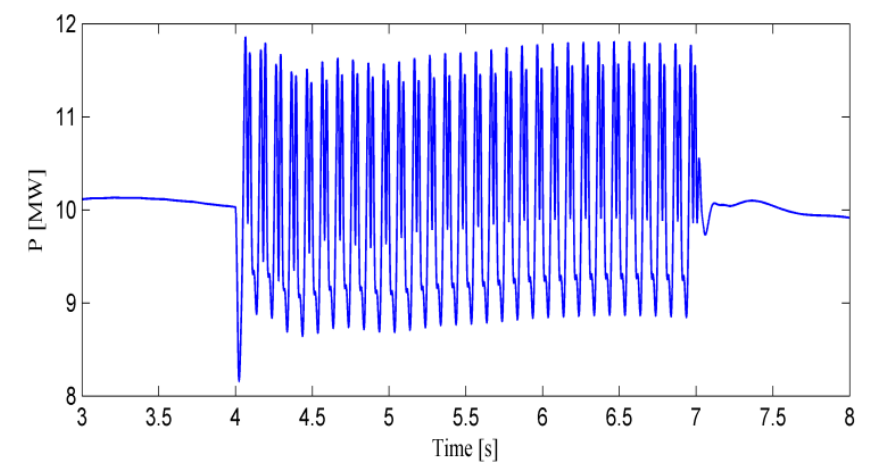

(a)

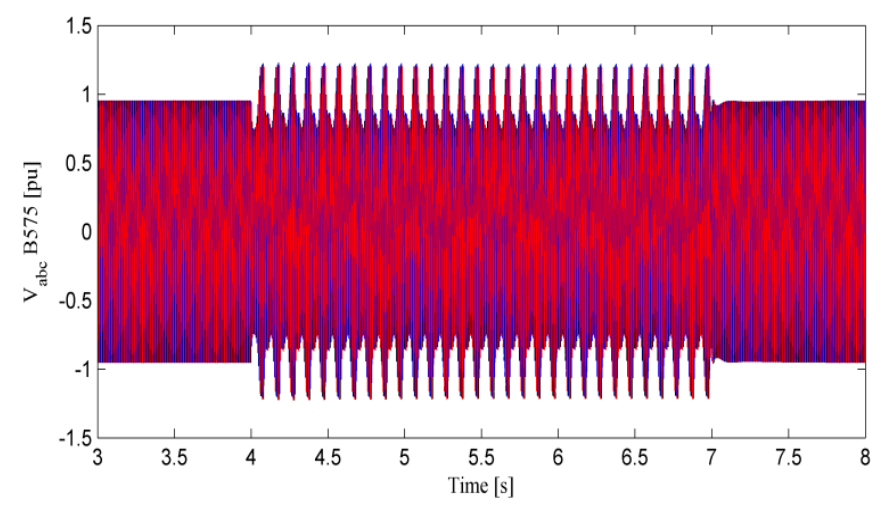

(b)

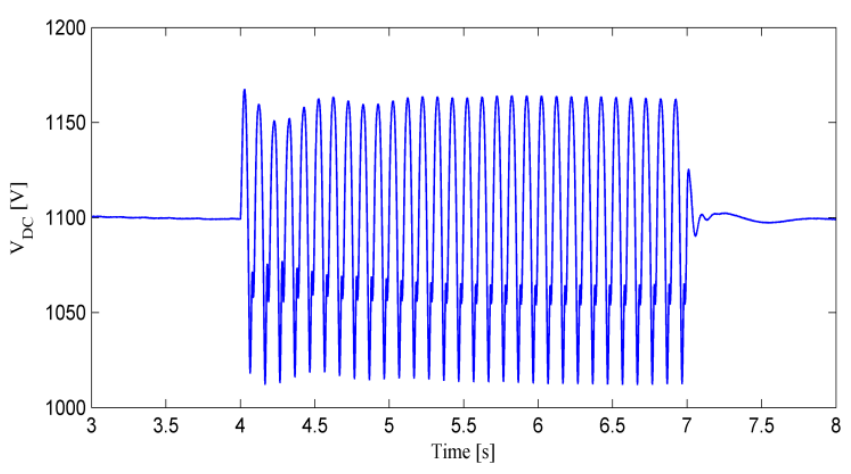

(c)

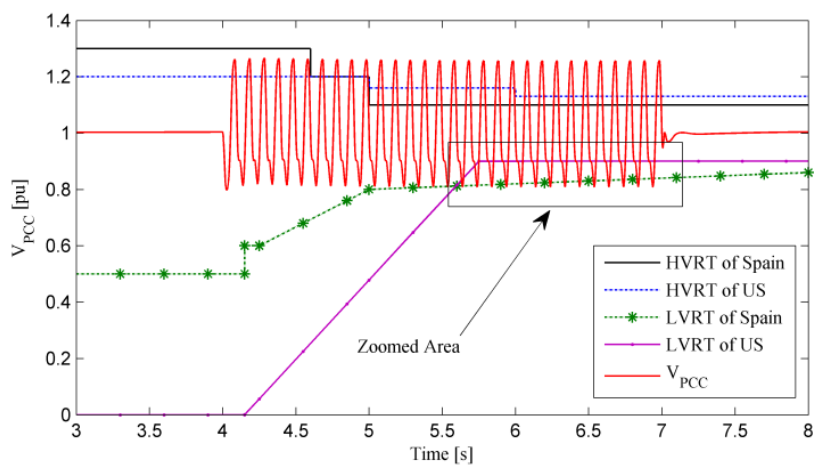

(d)

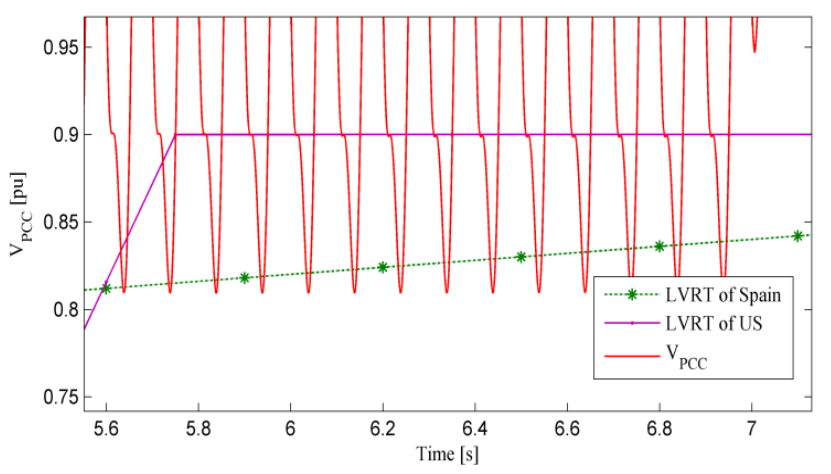

(e)

Fig.5 Impact of near flicker source on FCWECS' parameters (a) Generated power, (b) Generator terminal voltage, (c) DC link voltage (d) Voltage at PCC in comparison with HVRT of Spain and US and (e) Zoomed -voltage at PCC in comparison with LVRT of Spain and US

As flicker source may remain up to several minutes or even hours, a compensator is obligatory to be installed at the PCC to increase system damping and to suppress the flicker impacts. The application of compensators such as STATCOM and super conducting magnetic energy storage (SMES) unit that might be applicable for other purposes as discussed in [17]-[20] are preferred. The improvement of WTG's controller is another possible solution to the problem however, this would be suitable for new WTGs installation particularly for wind farm, as replacement and dismantle of the existing obsolete WTG will be costly compared to connecting a multipurpose compensator to the PCC.

\section{CONCLUSION}

This paper investigates the impact of flicker source on the overall performance of FCWECS and its compliance with the 
Spain and US grid codes. Results show that the flicker event will lead to the disconnection of WTGs from the grid as the voltage profile at the point of common coupling violates the HVRT and LVRT regulation of both Spain and US grid codes. The disconnection of $10 \mathrm{MW}-\mathrm{WTG}$ is obviously resulting in significant economic losses and power discontinuity to the load. Therefore, an effective compensator to increase system damping and to suppress the impact of flicker disturbance should be taken into consideration to avoid such severe impacts.

\section{APPENDIX}

PARAMETERS OF TYPE-4

\begin{tabular}{|c|c|}
\hline Rated Power & $10 \mathrm{MW}(5 \mathrm{x} @ 2 \mathrm{MW})$ \\
\hline Stator Voltage & $575 \mathrm{~V}$ \\
\hline Frequency & $60 \mathrm{~Hz}$ \\
\hline $\mathrm{R}_{\mathrm{S}}$ & $0.006 \mathrm{pu}$ \\
\hline $\mathrm{V}_{\mathrm{DC}}$ & $1100 \mathrm{~V}$ \\
\hline
\end{tabular}

PARAMETERS OF TRANSMISSION LINE

\begin{tabular}{|c|c|}
\hline $\mathrm{R}_{1}, \mathrm{R}_{0}(\Omega / \mathrm{km})$ & $0.1153,0.413$ \\
\hline $\mathrm{L}_{1}, \mathrm{~L}_{0}(\mathrm{H} / \mathrm{km})$ & $1.05 \times 10^{-3}, 3.32 \times 10^{-3}$ \\
\hline $\mathrm{C}_{1}, \mathrm{C}_{0}(\mathrm{~F} / \mathrm{km})$ & $11.33 \times 10^{-9}, 5.01 \times 10^{-9}$ \\
\hline
\end{tabular}

\begin{tabular}{|c|c|}
\multicolumn{2}{|c|}{ PARAMETERS OF LOADS } \\
\hline Load & $1.0 \mathrm{MW}$ \\
\hline \multirow{2}{*}{ Variable Load } & Nominal Load $=5000 \mathrm{~A}$, \\
& $\mathrm{Pf}=0.9$ \\
\hline
\end{tabular}

\section{ACKNOWLEDGMENT}

The author would like to thank the Higher Education Ministry of Indonesia (DIKTI) and the State Polytechnic of Ujung Pandang in supporting the research.

\section{REFERENCES}

[1] P. Musgrove, Wind Power, New York: Cambridge University Press, pp. 221-222. 2010

[2] J. M. Carrasco, L. G. Franquelo, J. T. Bialasiewicz, E. Galvan, R. C. P. Guisado, M. A. M. Prats, J. I. Leon, and N. Moreno-Alfonso, "Power-Electronic Systems for the Grid Integration of Renewable Energy Sources: A Survey", Industrial Electronics, IEEE Transactions on, vol. 53, pp. 1002-1016.2006

[3] P. W. Carlin, A. S. Laxson, and E. B. Muljadi, "The history and state of the art of variable-speed wind turbine technology," NREL, Colorado. 2001

[4] T. Ackermann, Wind Power in Power System, West Sussex: John Wiley and Sons Ltd, pp. 65. 2005

[5] http://www.world-nuclear.org/info/inf16.html, accessed. 31 July, 2012

[6] J. Arrillaga, N. R. Watson, and Chen, S., Power System Quality Assesment: John Wiley \& Sons. 2000

[7] M. H. J. Bollen, Understanding Power Qualtiy Problems: IEEE Press Series on Power Engineering. 2000

[8] B. W. Kennedy, Power Quality Primer: McGraw-Hill. 2000

[9] J. Schlabbach, D. Blume, and T. Stephanblome, Voltage Quality in Electrical Power System: The Institution in Electrical Power System. 2001

[10] C. Sankaran, Power Quality: CRC Press. 2002

[11] E. F. Fuchs, and M. A. S. Masoum, Power Quality in Power Systems and Electrical Machines: Elsivier. 2008

[12] http://www.copperinfo.co.uk/power-quality/downloads/pqug/514-flick er.pdf, accessed. 31 July 2012

[13] R. C. Dugan, M. F. McGranaghan, and H. W. Beaty, Electrical Power System Quality: McGraw-Hill. 1996

[14] M. Maana, , A. Ortiz, F. J. Azcondo, F. J. Diaz, F. Gonzalez, and C. Renedo, Flicker impact on 150 W HPS Lamps of different ages, in 9th International Conference on Electrical Power Quality and Utilisation, 2007. EPQU 2007, pp. 1-6. 2007

[15] X. Yang and I. Papic, Study of flicker propagation in electric grid by modeling and on-site flicker measurements, in Power and Energy Society General Meeting, 2010 IEEE, pp. 1-5 .2010
[16] A. M. Shiddiq-Yunus, M. A. S. Masoum, and A. Abu-Siada, "Impact of Intermittent Misfire and Fire-through on the Performance of Full Converter Based WECS in Innovative Smart Grid Technologies (ISGT) Australiasia Universities Power Engineering Conference (AUPEC 2012), , Bali, Indonesia. 2012

[17] A. M. Shiddiq-Yunus, A. Abu-Siada, and M. A. S. Masoum, "Improvement of LVRT Capability of Variable Speed Wind Turbine Generators Using SMES Unit," in Innovative Smart Grid Technologies (ISGT) Asia, IEEE PES, Perth, Western Australia. 2011

[18] A. M. Shiddiq Yunus, A. Abu-Siada, and M. A. S. Masoum, "Effect of SMES unit on the performance of type-4 wind turbine generator during voltage sag," in, IET Conference on Renewable Power Generation (RPG 2011), pp. 1-4. 2011

[19] A. M. Shiddiq Yunus, M. A. S. Masoum, and A. Abu-Siada, "Effect of STATCOM on the low-voltage-ride-through capability of Type-D wind turbine generator," in Innovative Smart Grid Technologies Asia (ISGT), 2011 IEEE PES, pp. 1-5. 2011

[20] A. M. Shiddiq-Yunus, A. Abu-Siada, and M. A. S. Masoum: 'Effects of SMES on Dynamic Behaviours of Type D-Wind Turbine Generator-Grid Connected during Short Circuit'. IEEE PES meeting, Detroit, USA. 2011

[21] http://www.icrepq.com/icrepq'12/698-mercado.pdf, accessed 19 November 2012

[22] F. Zhou, G. Joos, C. Abbey, L. Jiao, and B. T. Ooi, "Use of large capacity SMES to improve the power quality and stability of wind farms," in Proc. IEEE Power Engineering Society General Meeting, vol. 2, pp. 2025-2030. 2004

[23] M. H. Ali, T. Murata, and J. Tamura, "Minimization of fluctuations of line power and terminal voltage of wind generator by fuzzy logic-controlled SMES,” Int. Rev. Elect. Eng. (IREE), vol. 1, no. 4 pp. 559-566. 2006

[24] T. Asao, R. Takahashi, T. Murata, J. Tamura, M. Kubo, A Kuwayama,and T. Matsumoto, "Smoothing control of wind power generator output by superconducting magnetic energy storage system," in Proc. Int. Conf. Electrical Machines and Systems 2007 (ICEMS 2007), pp. 302-307. 2007

[25] I. Ngamroo, A. N. C. Supriyadi, S. Dechanupaprittha, and Y. Mitani, "Power oscillation suppression by robust SMES in power system with large wind power penetration," J. Physica C, Supercond., vol. 469, no. 1, pp. 44-51. 2009.

[26] X. Altin, R. Goksu, P. Teodorescu, B. Rodriguez, B. Jensen, and L. Helle, "Overview of recent grid codes for wind power integration," in 12th International Conference on Optimization of Electrical and Electronic Equipment (OPTIM), 2010, pp. 1152-1160. 2010

[27] V. Akhmatov, "Analysis of Dynamic Behaviour of Electric Power System with Large Amount of Wind Power," in Electrical Power Engineering Lyngby: Technical University of Denmark, 2003. 